\title{
Mathematics education, democracy and development: A view of the landscape
}

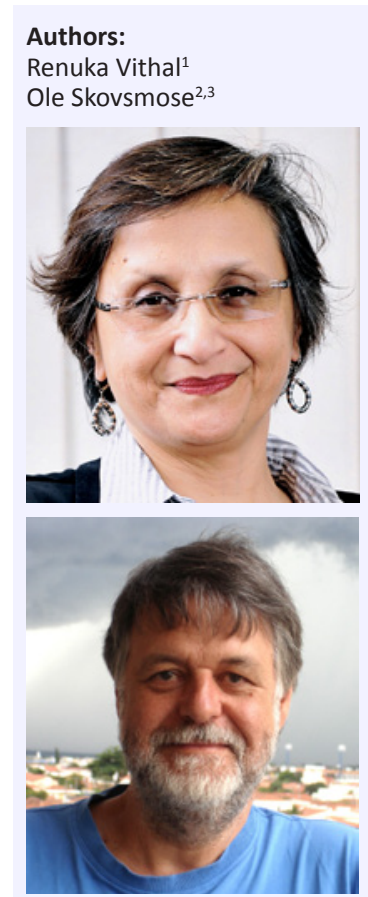

Affiliations:

${ }^{1}$ School of Education, University of KwaZulu-Natal, South Africa

${ }^{2}$ Department of Learning and Philosophy, Aalborg University, Denmark

${ }^{3}$ Graduate Programme in Mathematics Education, Universidade Estadual Paulista, Brazil

Correspondence to: Renuka Vithal

Email:

vithalr@ukzn.ac.za

Postal address:

Howard College Campus,

2nd Floor Francis Stock

Building, Mazisi Kunene

Road, Glenwood, Durban,

South Africa

How to cite this editorial: Vithal, R., \& Skovsmose, O. (2012). Mathematics education, democracy and development: A view of the landscape. Pythagoras, 33(2), Art. \#207, 3 pages. http://dx.doi.org/10.4102/ pythagoras.v33i2.207

C 2012. The Authors. Licensee: AOSIS OpenJournals. This work is licensed under the Creative Commons Attribution License.
The links between mathematics education and democracy have been explored in a growing amount of literature. One might even claim a resurgence of the importance of this aspect in the current climate of financial crises and the 'Arab Spring.' The theme, for instance, of the 2012 conference of the International Commission for the Study and Improvement of Mathematics Education was 'Mathematics education and democracy: Learning and teaching practices'. The conference raised questions about democracy in the mathematics curriculum, in the mathematics classroom, in teacher education and in research. Much of the writing in this area is, however, contextualised with reference to the so-called 'developed world': to the risks posed to long established democracies experiencing, rapid advances in science and technology and related societal changes. Given the foundational place and role of mathematics in key areas of science, technology and the economy, questions emerge more forcefully about the kinds of mathematics and mathematics education needed, for whom, and how best to deliver these in diverse but also rapidly and unpredictably changing societies.

The late eighties and early nineties are important to recognise for the theme of this special issue. In particular, Scandinavian scholars were exploring theory and practices in education to strengthen their democracy, which coincided with the dawn of democracy in South Africa and a period of rethinking the post-apartheid education system. It was also a period of ferment in mathematics education as, for example, the first conference on the Political Dimension in Mathematics Education Conference (Noss et al., 1990) was convened and the cultural dimensions of mathematics education were being put forward through research and practices in areas such as ethnomathematics.

\section{Mathematics in action}

Mathematics operates in a variety of cultural and sociopolitical practices. It is part of everyday situations, professional contexts, technological enterprises and research procedures. It operates as part of a worldwide distributed technical rationality, which can be analysed in terms of mathematics in action (Skovsmose, 2005; Christensen, Skovsmose \& Yasukawa, 2008): we send emails, we use credit cards, we contract loans, we get insured. Workplaces include mathematics practices: part of production is automated, quality control takes place, cost-benefit analyses are conducted, goods are brought to the market, prices are set and advertised. All these practices are mathematics heavy. So is political decision-making where, for instance, implications of alternative economic policies are investigated through simulation models. Mathematics is operating in technologies of surveillance, in health care, in weather forecasting and in ecological forecasting concerning the state of world. Mathematics is a part of any form of technological enterprise as well as research processes in technology and science. Globalised networking, with respect to communication, economy, production, distribution of welfare and poverty and social inclusion and exclusion, includes mathematics put into action.

If we consider the scope of mathematics in action, it is not surprising that there is a huge concern for managing, in an efficient and proficient way, mathematics curricula as part of the educational system - a concern which recently has been expressed through international comparisons of students' performances in mathematics. Mathematics education signifies a worldwide means of developing and distributing a set of competencies and of labelling people through a finely graded exam system. At all levels of the general educational system, mathematics is a crucial component. It also forms part of a broad range of further education within science, technology, engineering, medicine, economy, management, et cetera. It would appear that mathematics education is responding to the fundamental demands of the modern labour market, which now takes the form of a knowledge market.

Mathematics and mathematics education are enacted in and are implicated in an increasingly uncertain world, a world in which technology has become pervasive and seeped into almost all facets of people's lives: we may refer to the rapid spread of mobile phone technology in Africa, for 
example. Technological determinism holds that technological development sets the course of social development in general. An optimistic form of this determinism finds that technological development - due to its intrinsic laws and to the fact that it is science based - will eventually ensure social welfare on a grand scale. Contrary to this, a pessimistic technological determinism depicts technology as a highway to a dehumanised world, due to the very rationality of it. We find moving beyond any form of determinism means moving beyond both optimism and pessimism.

\section{Uncertainties and contingencies}

Mathematics-based technology brings us deep into a terrain of uncertainties and contingencies. Situations are produced which can take society in very different directions. Predictability of what technological innovations will emerge, how technology will be applied and with what consequences is minimal. Different forms of development are leaping forth in a hazardous way, due to a technologically produced density of contingencies (Skovsmose, 2005). Mathematics in action makes up part of this terrain of contingencies. It is an integral part of an uncertain world. To illustrate this point: on the one hand, exploitation of natural resources is driven by technology, operating through a mathematically expressed rationality; on the other hand, mathematics enters into the models through which we seek to provide forecasts concerning the impact of those same technological enterprises. Any long-term ecological implications cannot be identified without using mathematics-based models of simulation and forecasting. Naturally, any such forecasting might be wrong - but whatever it is, it depends on mathematics. Mathematics plays an important role in a huge variety of practices, the nature of which may differ greatly. These roles are not qualified in any particular way due to some assumed nature of mathematics. Instead, mathematics forms part of technologically produced uncertainties.

Mathematics education forms part of open-ended social processes. On the one hand, one might assume that mathematics education blindly adapts to the demands for competencies expressed in dominant economic and technological structures. Thus, one may interpret mathematics education as a way of developing a competency in following manuals, as a way of developing a prescription readiness, which is important in a multiplicity of work practices (Skovsmose, 2008). On the other hand, mathematics education operates on market conditions in a globalised economy, where processes of inclusion and exclusion operate, not least through the educational system. There is, however, no transparent relationship between the competencies a mathematics education might provide and those competencies that mathematics-dense practices might presuppose. Thus, one might find that mathematics education establishes citizenship and reflective insight in some situations for some students. Mathematics education might even ensure new opportunities in life for groups of young people. It may be part of a string of processes of 'social justice,' and very many suggestions for what this could mean have been put forward. So, mathematics education is a crucial part of an unpredictable world.

\section{A view of the landscape}

The extent to which links between mathematics education and democracy have been explored in a range of studies, in different parts of the world, is documented in this special issue in the literature review provided by Aguilar and Zavaleta.

Two articles make different proposals for mathematics education and this uncertainty. Swanson and Appelbaum put forward 'refusal and disobedience' as democratic action in mathematics education. They argue that 'globalisation and development discourses, via citizenship and nationalism, construct relationships with learners and mathematics education in very specific ways that delimit possibilities for egalitarianism.' Refusal 'as a position of radical equality' is a 'refusal to participate in mathematics education's colonising and/or globalising neo-liberal gaze.' Valero, Garcia, Camelo, Mancera and Romero propose that democracy be understood 'in terms of the possibility of constructing a social subjectivity for the dignity of being' and illustrate this possibility in mathematics education through 'reassembling' geometrical space in the Columbian secondary school mathematics curriculum. Drawing on notions of space from critical geography, the problem of territorialisation and Latin American social epistemology, they show how 'mathematical spaciality' can be transcended 'to social space and intimate space.' They argue that 'decentring of the school mathematics curriculum may open the possibility for an educational project in mathematics that allows for different subjectivities.'

Several articles show a concern with pedagogy and practice in mathematics classrooms. Teacher practices such as 'listening' and being able to 'promote dialogue and negotiation' are engaged in three research articles based in the South African context: Khuzwayo and Bansilal; Mhlolo and Schafer; and Brijall, Bansilal and Moore-Russo. Related to this, authors also emphasise the issue of 'student voice.' Daher, writing from the Palestinian context about student teachers' perceptions of democracy in their mathematics class, describes how students want opportunities to express themselves in mathematics classrooms and to be allowed to be in 'control of their actions.'

A conceptual development related to students with respect to democracy and mathematics education is the notion of 'foregrounds,' developed by Skovsmose. It refers to the future possibilities that a context reveals and provides for a person. In this special issue article Skovsmose consolidates the concept of 'students' foreground' by elaborating its educational meaning with respect to activities in the mathematics classroom. He shows how a 'foreground might be ruined' and turned into 'a learning obstacle.' Using this same notion of foreground, but with reference to teachers, Amin demonstrates, through memory work, 'how exposure to mathematics teaching and learning when they were 
learners is implicated in shaping the foregrounds of teachers.' In this way, Amin provides an important new dimension to the discussions of foregrounds.

It is clear that bringing democracy into mathematics education has many and varied implications for pedagogy. In her article, Vithal extends a pedagogy of conflict and dialogue to integrate a pedagogy of forgiveness for a postconflict society like South Africa. This extension enables values of equity, social justice and reconciliation to become part of a mathematics curriculum. Allied to the call for acknowledging social subjectivities and the dignity of being in the content of a mathematics curriculum by Valero et al., Vithal utilises, as a metaphor, South Africa's Truth and Reconciliation framework of multiple truths for bringing into dialogue and negotiation 'multiple truths in mathematics.' In this way, she attempts to connect a broad range of competing and cooperating developments in mathematics and mathematics education.

\section{Contested notions}

There is no doubt that in the triad of mathematics education, democracy and development, the concepts of democracy and development are deeply contested notions. The challenges faced by Western or wealthy nations in this relation between mathematics education and democracy are, of course, also present in the context of societies variously described as 'developing,' 'periphery,' 'South,' or 'Third World' in today's networked and globalised world. But countries like South Africa must engage simultaneously with, on the one hand, mathematics education and its role and function to deepen and strengthen democracy, and, on the other hand, enable and sustain key areas of development in order to overcome deep divisions, high levels of poverty and inequality.
The notion of 'development' as it features in 'development studies' or in discussions of a 'developmental state' has not found any substantive voice in mathematics education literature. This, despite the fact that a vast majority of mathematics teaching and learning takes place in developing contexts with a lack of different human and physical resources. Notwithstanding progress made in areas such as ethnomathematics, gender and equity, concerns about 'development' are still not profoundly researched and theorised in mathematics education. Poverty and its related issues (e.g. youth unemployment), which have many implicit and explicit connections to mathematics education, do not seem to feature strongly in mainstream mathematics education research, literature, conferences and in theorising mathematics teaching and learning, even though they have major policy implications. However, some small movements in this area are emerging as can be seen in this special issue, in a survey team presentation on 'Socio-economic influences on students' achievement' at the most recent International Congress on Mathematical Education (ICME-12), as well as in the successive Mathematics Education and Society conferences. These are likely to grow and become much more important for mathematics education in the future.

\section{References}

Christensen, O.R., Skovsmose, O., \& Yasukawa, K. (2008). The mathematical state of the world: Explorations into the characteristics of mathematical descriptions. Alexandria Journal of Science and Technology Education 1(1), 77-90.

Noss, R., Brown, A., Dowling, P., Drake, P., Harris, M., Hoyles, C., et al. (Eds.). (1990) Political dimensions of mathematics education: Action and critique. London: Institute of Education, University of London. PMid:2378711

Skovsmose, O. (2005). Travelling through education: Uncertainty, mathematics, responsibility. Rotterdam: Sense Publishers.

Skovsmose, O. (2008). Mathematics education in a knowledge market. In E. de Freitas, $\&$ K. Nolan (Eds.), Opening the research text: Critical insights and in(ter)ventions into mathematics education (pp. 159-174). New York, NY: Springer. 